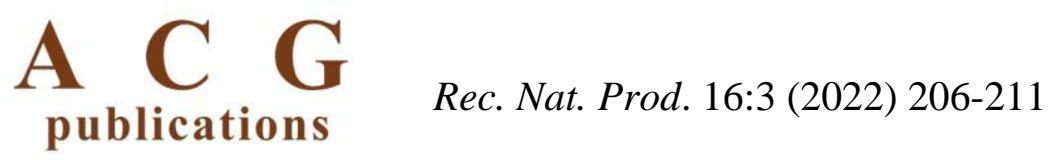

\title{
Two New 13-oxomilbemycins from a NTG-Induced Mutation Strain of Streptomyces avermitilis AVE-H39
}

\author{
Ji-Dong Wang $\oplus^{1}$, Bing Li $\oplus^{1}$, Shao-Yong Zhang $\oplus^{1}$, Yi Wu $\oplus^{1}$, \\ Wen-Sheng Xiang $\oplus^{2}$, Li-Qin Zhang $\oplus^{1}$ and Huan Qi $\oplus^{1^{*}}$
}

\author{
${ }^{1}$ Key Laboratory of Vector Biology and Pathogen Control of Zhejiang Province, \\ College of Life Science, Huzhou University, Huzhou 313000, China \\ ${ }^{2}$ Life Science and Biotechnology Research Center, School of Life Science, Northeast \\ Agricultural University, Harbin 150030, China
}

(Received May 14, 2021; Revised July 06, 2021; Accepted July 08, 2021)

\begin{abstract}
Two new 13-oxomilbemycins, 13-oxomilbemycin $\beta_{3}$ (1) and 25-ethyl-13-oxomilbemycin $\beta_{3}(\mathbf{2})$, were isolated from the broth of a NTG-induced mutation strain of Streptomyces avermitilis AVE-H39. The structures of $\mathbf{1}$ and $\mathbf{2}$ were determined based on MS and extensive NMR analysis. Compounds $\mathbf{1}$ and $\mathbf{2}$ possessed moderate nematocidal activity.
\end{abstract}

Keywords: Streptomyces avermitilis AVE-H39; NTG-induced mutation; 13-oxomilbemycins; nematocidal activity. (C) 2021 ACG Publications. All rights reserved.

\section{Introduction}

Sixteen-membered macrolides, important members of the polyketides, have been widely used in veterinary and agricultural fields and obtained great success [1-3]. Because of its wide-spread applications, researches on sixteen-membered macrolides are of great interest worldwide. Recently, a new kind of 16-membered macrolide antibiotics (tenvermectins A and B) with better insecticidal property than avermectin and ivermectin have been isolated from the fermentation broth of the two genetically engineered strains Streptomyces avermitilis MHJ1011 and Streptomyces avermitilis AVE$\mathrm{H} 39$ [4-5]. In the effort to enhance the production of tenvermectins A and B in S. avermitilis AVE$\mathrm{H} 39$, a mutant strain AVE-H39C12 was obtained by treating the spores of $S$. avermitilis AVE-H39 with $N$-methyl- $N$ '-nitroso- $N$-nitrosoguanidine. Several differences of the HPLC profiles of metabolites were observed between the strain S. avermitilis AVE-H39 and its mutant strain AVE-H39C12. As part of an ongoing search for the metabolites of this mutant strain, two new interesting compounds were isolated from the fermentation broth of $S$. avermitilis AVE-H39C12. Here we described the isolation, structural elucidation and nematocidal activity of the two new compounds.

\footnotetext{
*Corresponding author: E-Mail: 1cqhlc@163.com (H. Qi); Phone:+86-572-2321166
} 
Wang et al., Rec. Nat. Prod. (2022) 16:3 206-211

\section{Materials and Methods}

\subsection{General}

Optical rotation was measured on Perkin-Elmer 341 Polarimeter (Perkin-Elmer, Suzhou, China). IR spectra in pressed $\mathrm{KBr}$ disk were obtained on a Thermo Scientific Nicolet iS20 FTIR spectrometer (Thermo Scientific, Waltham, MA, USA) and UV spectra were recorded on a Thermo Scientific Evolution $201 \mathrm{UV}-$ Visible spectrophotometer (Thermo Scientific, Waltham, MA, USA). ${ }^{1} \mathrm{H}$ and ${ }^{13} \mathrm{C}$ NMR spectra were recorded on a Bruker DRX-400 spectrometer $\left(400 \mathrm{MHz}\right.$ for ${ }^{1} \mathrm{H}$ and 100 $\mathrm{MHz}$ for ${ }^{13} \mathrm{C}$; Bruker, Rheinstetten, Germany). Chemical shifts are reported in ppm $(\delta)$, using $\mathrm{CDCl}_{3}$ $\left(\delta_{\mathrm{H}} 7.27 ; \delta_{\mathrm{C}} 77.0\right)$ as an internal standard, and coupling constants $(J)$ in Hz. The ESIMS and HRESIMS were taken on an Agilent 6545 Q-TOF LC-MS-MS mass spectrometer (Agilent, Palo Alto, CA, USA). Column chromatography was carried out on silica gel (100-200 mesh; Qingdao Marine Chemical Group Co., Qingdao, Shandong, China) and Sephadex LH-20 (GE Healthcare, Glies, UK). Preparative HPLC (Agilent 1200, Zorbax SB-C18, $5 \mu \mathrm{m}, 250 \times 20 \mathrm{~mm}$ inner diameter; $10 \mathrm{~mL} / \mathrm{min} ; 220 \mathrm{~nm}$; Agilent, Palo Alto, CA, USA) was further performed to obtain pure compounds. Spots were detected on thin layer chromatography (TLC) under UV or by heating after spraying with sulfuric acid-ethanol $(5: 95, \mathrm{v} / \mathrm{v})$.

\subsection{Organisms Material}

The parental strain $S$. avermitilis AVE-H39 was grown and maintained on ISP2 agar plate containing malt extract (Becton, Dickinson and Company, Franklin Lake, NJ, USA) 1\%, yeast extract (Oxoid Ltd, Basingstoke, UK) 0.4\%, glucose (Sinopharm Chemical Reagent Co, Ltd, Shanghai, China) $0.4 \%$, and agar (Sinopharm Chemical Reagent Co, Ltd, Shanghai, China) 2.0\% at pH 7.0. To improve the production of tenvermectins A and B, spores of $S$. avermitilis AVE-H39 were treated with $N$-methyl- $N$ '-nitroso- $N$-nitrosoguanidine (NTG) using the described method [6-8]. Mutant colonies were obtained by incubation for 7-12 days at $28{ }^{\circ} \mathrm{C}$. Each colony was fermented by shake flask with $30 \mathrm{~mL}$ medium consisted of corn starch (Shandong Xiwang Group Ltd, Binzhou, China) 10\%, amylase (Sinopharm Chemical Reagent Co, Ltd, Shanghai, China) $0.02 \%$, soybean powder (Ningbo Beilun Jiangnan Grease Co, Ltd, Ningbo, China) 2.0\%, yeast extract (Angel Yeast Co., Ltd, Yichang, China) $1.0 \%, \mathrm{CaCO}_{3}$ (Sinopharm Chemical Reagent Co, Ltd, Shanghai, China) $0.2 \%$, on a rotary shaker $\left(250 \mathrm{rpm}, 28^{\circ} \mathrm{C}\right)$ for 7 days. The profiles of the fermentation products were analyzed by HPLC. As a result, several differences on the HPLC profiles were observed between the strain $S$. avermitilis AVE-H39 and its mutant strain AVE-H39C12. Thus, the mutant strain AVE-H39C12 was used for further study.

\subsection{Fermentation and Isolation}

The mutant strain S. avermitilis AVE-H39C12 was incubated on ISP2 agar plates for 8 days at $28{ }^{\circ} \mathrm{C}$, and then the spores were inoculated in the $1 \mathrm{~L}$ Erlenmeyer flasks with seed medium. Each flask contained $250 \mathrm{~mL}$ of seed medium consisted of glucose $0.4 \%$, maltodextrin (Shandong Xiwang Group Ltd, Binzhou, China) $1 \%$, yeast extract $0.4 \%, \mathrm{CaCO}_{3} 0.2 \%, \mathrm{pH} 7.2$, and the medium was sterilized for 20 minutes at $121^{\circ} \mathrm{C}$. After incubated on a rotary shaker $\left(250 \mathrm{rpm}, 28^{\circ} \mathrm{C}\right)$ for $48 \mathrm{~h}$, about $1 \mathrm{~L}$ of the seed were inoculated in a $50 \mathrm{~L}$ fermentor (Shanghai Baoxing Bioengineering Equipment Co. Ltd., China) which contained $30 \mathrm{~L}$ of production medium consisting of corn starch $12 \%$, amylase, $0.02 \%$, soybean powder 3.0\%, yeast powder (Angel Yeast Co., Ltd, Yichang, China) 1.0\%, mannitol (Qingdao Bright Moon Seaweed Group Co., Ltd., China) 2.0\%, $\mathrm{CaCO}_{3} 0.3 \%$, defoaming $0.1 \%$, pH 7.2. The fermentation was carried out at $28{ }^{\circ} \mathrm{C}$ for 8 days and stirred at $200 \mathrm{rpm}$ with the aeration rate of $1500 \mathrm{~L}$ of air per hour, tank pressure control at $0.05 \mathrm{MPa}$.

The final $30 \mathrm{~L}$ of fermentation broth was filtered and the resulting cake was extracted with ethanol $(10 \mathrm{~L})$. The ethanol extract was evaporated under reduced pressure to $1 \mathrm{~L}$ at $45{ }^{\circ} \mathrm{C}$ and 
Two new 13-oxomilbemycins from Streptomyces avermitilis

subsequently extracted three times using an equal volume of ethyl acetate. The combined ethyl acetate phase was concentrated under reduced pressure and the crude extract was subjected to a silica gel column and successively eluted with a stepwise gradient of petroleum ether/EtOAc (90:10-60:40, v/v) to yield six fractions (I-VI) based on the TLC profiles. The fraction II was separated by Sephadex LH20 column eluting with $\mathrm{CH}_{2} \mathrm{Cl}_{2} / \mathrm{MeOH}(1 / 1, \mathrm{v} / \mathrm{v})$ to afford fraction IIA. Fraction IIA was further purified by preparative HPLC eluting with $\mathrm{MeOH} / \mathrm{H}_{2} \mathrm{O}\left(85: 15, \mathrm{v} / \mathrm{v}, 10 \mathrm{~mL} \mathrm{~min}^{-1}\right)$ to give compounds 1 $\left(11 \mathrm{mg}, t_{\mathrm{R}}=17.5 \mathrm{~min}\right)$ and $\mathbf{2}\left(16 \mathrm{mg}, t_{\mathrm{R}}=19.8 \mathrm{~min}\right)$.

Compound 1: Colorless oil; $[\alpha]_{D}^{25}+51$ ( $c$ 0.07, EtOH); UV (EtOH) $\lambda_{\max } \mathrm{nm}(\log \varepsilon): 233$ (4.50); IR (KBr) $v_{\max } \mathrm{cm}^{-1}: 3371,2929,1672,1452,1380,1278,1166,1094,1003 ;{ }^{1} \mathrm{H}$ NMR $\left(400 \mathrm{MHz}, \mathrm{CDCl}_{3}\right)$ and ${ }^{13} \mathrm{C}$ NMR (100 MHz, $\mathrm{CDCl}_{3}$ ) spectral data are listed in Table 1; HRESIMS: $m / z$ 509.2909 [M + $\mathrm{H}]^{+}$(calcd for $\mathrm{C}_{31} \mathrm{H}_{41} \mathrm{O}_{6}, 509.2898$ ).

Compound 2: Colorless oil; $[\alpha]_{D}^{25}+48$ (c 0.15, EtOH); UV (EtOH) $\lambda_{\max } \mathrm{nm}(\log \varepsilon): 227$ (4.56); IR $(\mathrm{KBr}) v_{\max } \mathrm{cm}^{-1}: 3384,2929,1707,1455,1380,1278,1165,1100,988 ;{ }^{1} \mathrm{H}$ NMR $\left(400 \mathrm{MHz}, \mathrm{CDCl}_{3}\right)$ and ${ }^{13} \mathrm{C}$ NMR (100 MHz, $\left.\mathrm{CDCl}_{3}\right)$ spectral data are listed in Table 1; HRESIMS: $m / z 523.3060[\mathrm{M}+$ $\mathrm{H}]^{+}$(calcd for $\mathrm{C}_{32} \mathrm{H}_{43} \mathrm{O}_{6}, 523.3054$ ).

\subsection{Nematicidal Activity}

The nematicidal activities of compounds 1-2 against Bursaphelenchus xylophilus were tested according to the described method using the commercial milbemycins A3/A4 as a positive control [4].

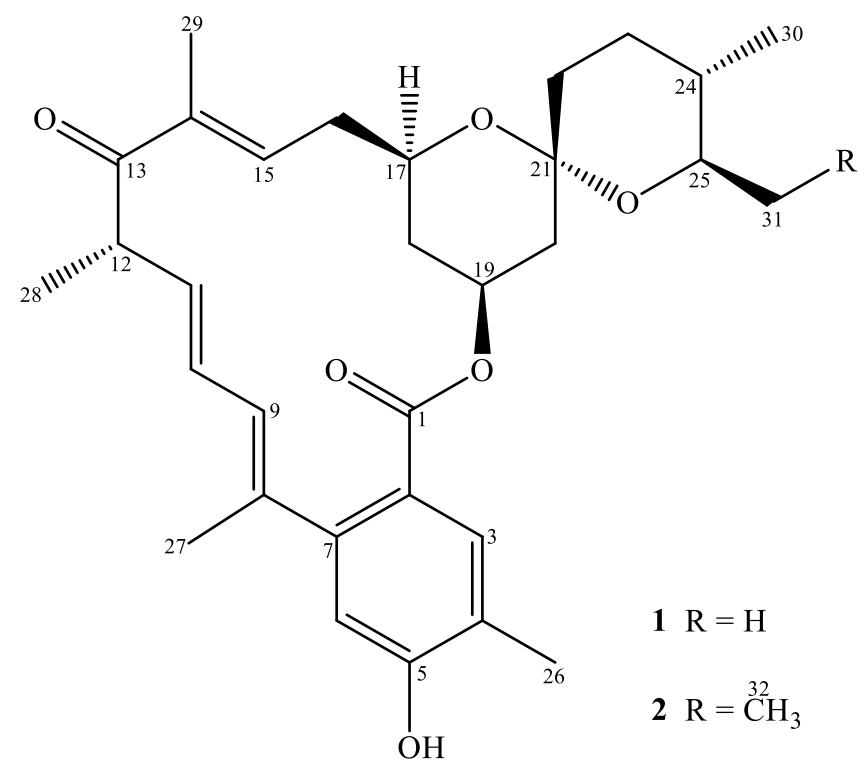

Figure 1. Structures of compounds 1 and 2 


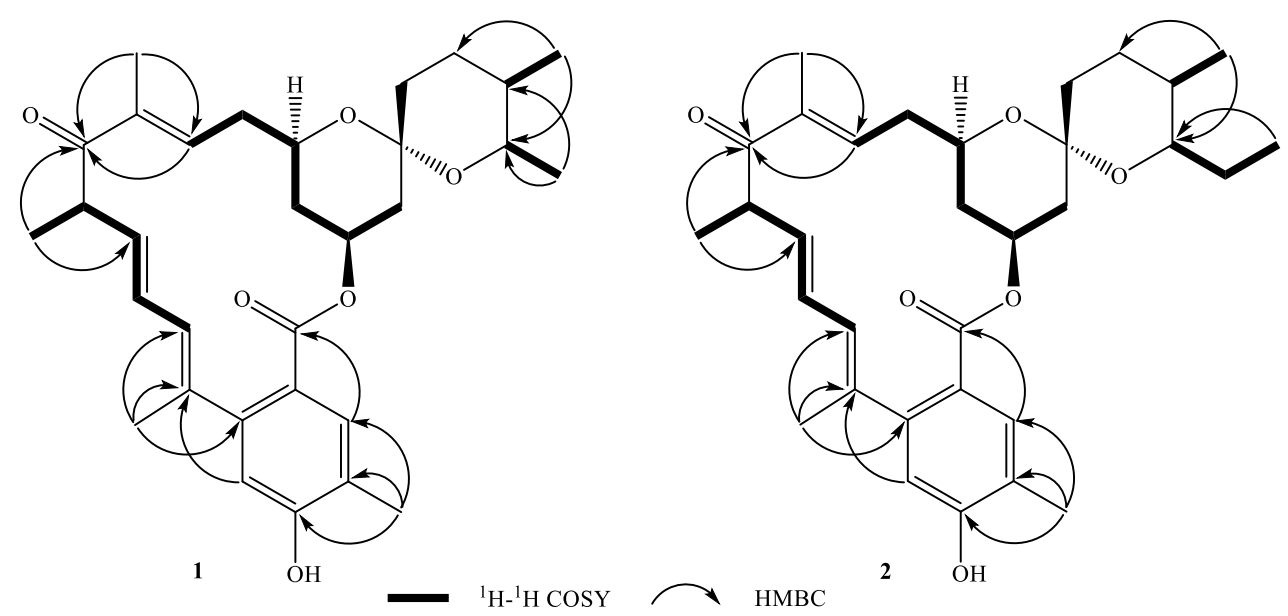

Figure 2. Key ${ }^{1} \mathrm{H}-{ }^{1} \mathrm{H}$ COSY and HMBC correlations of compounds $\mathbf{1}$ and 2.

\section{Results and Discussion}

\subsection{Structure Elucidation}

Compound 1 was obtained as colorless oil with a specific rotation of $[\alpha]_{\mathrm{D}}^{25}+51(c 0.07, \mathrm{EtOH})$ and $\mathrm{UV}(\mathrm{EtOH}) \lambda_{\max } \mathrm{nm}(\log \varepsilon): 233$ (4.50). Its molecular formula $\mathrm{C}_{31} \mathrm{H}_{40} \mathrm{O}_{6}$ was established by the positive HRESIMS ion at $\mathrm{m} / z$ 509.2909 $[\mathrm{M}+\mathrm{H}]^{+}$(calcd 509.2898), indicating 12 indices of hydrogen deficiency. Absorptions at 3371 and $1672 \mathrm{~cm}^{-1}$ in the IR spectrum of 1 revealed the presence of hydroxyl and carbonyl functionalities, respectively. The ${ }^{1} \mathrm{H}$ NMR spectrum of $\mathbf{1}$ (Table 1) showed the presence of two downfield singlet signals $\left[\delta_{\mathrm{H}} 7.50(1 \mathrm{H}, \mathrm{s})\right.$ and $\left.6.59(1 \mathrm{H}, \mathrm{s})\right]$, one trans-double bond $\left[\delta_{\mathrm{H}} 6.46(1 \mathrm{H}, \mathrm{dd}, J=15.0,10.9 \mathrm{~Hz})\right.$ and $\left.5.41(1 \mathrm{H}, \mathrm{dd}, J=15.0,9.5 \mathrm{~Hz})\right]$, an aromatic methyl $\left[\delta_{\mathrm{H}} 2.25\right.$ $(3 \mathrm{H}, \mathrm{s})]$, two olefinic methyls $\left[\delta_{\mathrm{H}} 2.12(3 \mathrm{H}, \mathrm{d}, J=0.9 \mathrm{~Hz})\right.$ and $1.81(3 \mathrm{H}$, brs $\left.)\right]$ and three aliphatic doublet methyls $\left[\delta_{\mathrm{H}} 1.22(3 \mathrm{H}, \mathrm{d}, J=6.7 \mathrm{~Hz}), 1.14(3 \mathrm{H}, \mathrm{d}, J=6.2 \mathrm{~Hz})\right.$ and $\left.0.85(3 \mathrm{H}, \mathrm{d}, J=6.5 \mathrm{~Hz})\right]$. Its ${ }^{13} \mathrm{C}$ NMR spectrum, complemented by DEPT experiment (Table 1) only exhibited 30 carbon resonances including two carbonyls [ $\delta_{\mathrm{C}} 202.1$ and 168.4], five $s p^{2}$ quaternary carbons, six protonated $s p^{2}$ carbons, one ketal carbon [ $\left.\delta_{\mathrm{C}} 97.7\right]$, five $s p^{3}$ methines (three of which contained oxygen), five $s p^{3}$ methylenes and six methyls. The HMBC correlations (Figure 2) from the two olefinic methyls to the carbon signal $\left(\delta_{\mathrm{C}} 137.7\right)$ suggested that two $s p^{2}$ quaternary carbons were overlapped at $\delta_{\mathrm{C}} 137.7$. The ${ }^{1} \mathrm{H}$ and ${ }^{13} \mathrm{C}$ NMR data of $\mathbf{1}$ revealed close similarities to those of milbemycin $\beta_{3}$ [9-10] except that a methylene at $\mathrm{C}-13$ in milbemycin $\beta_{3}$ was replaced by a carbonyl group in $\mathbf{1}$. The observed HMBC correlation from $\mathrm{H}_{3}-28$ and $\mathrm{H}_{3}-29$ to $\mathrm{C}-13\left(\delta_{\mathrm{C}} 202.1\right)$ established the structure of $\mathbf{1}$ as 13oxomilbemycin $\beta_{3}$. The downfield chemical shift of C-15 $\left(\delta_{\mathrm{H}} 6.71 ; \delta_{\mathrm{C}} 139.1\right)$ further confirmed the presence of a carbonyl group in C-13. From a biosynthetic point of view, the relative configuration of 1 was assigned as that of 25-methyl ivermectin [5].

Compound 2 was isolated as colorless oil with a positive optical rotation of of $[\alpha]_{\mathrm{D}}^{25}+48(c$ $0.15, \mathrm{EtOH})$ and UV $(\mathrm{EtOH}) \lambda_{\max } \mathrm{nm}(\log \varepsilon): 227$ (4.56). The molecular formula of 2 was established as $\mathrm{C}_{32} \mathrm{H}_{42} \mathrm{O}_{6}$ based on the HRESIMS ion at $\mathrm{m} / z$ 523.3060 $[\mathrm{M}+\mathrm{H}]^{+}$, implying 12 degrees of unsaturation. The IR spectrum showed absorption bands assignable to the carbonyl group $\left(1707 \mathrm{~cm}^{-1}\right)$ and the hydroxy group $\left(3384 \mathrm{~cm}^{-1}\right)$. A detailed analysis of the ${ }^{1} \mathrm{H}$ and ${ }^{13} \mathrm{C}$ NMR data of 2 (Table 1) revealed that it has the same skeleton as $\mathbf{1}$. The only difference between $\mathbf{2}$ and $\mathbf{1}$ was in the substituent of C-25, where the methyl group in $\mathbf{1}$ was replaced by an ethyl group in $\mathbf{2}$. The HMBC correlations (Figure 2) from $\mathrm{H}_{3}-32\left(\delta_{\mathrm{H}} 0.96\right)$ to $\mathrm{C}-25\left(\delta_{\mathrm{C}} 76.3\right)$ in conjunction with the crossing peak of $\mathrm{H}_{3}-32 / \mathrm{H}_{2}-$ 31 in the ${ }^{1} \mathrm{H}-{ }^{1} \mathrm{H}$ COSY spectrum (Figure 2) established the structure of $\mathbf{2}$ as 25-ethyl-13oxomilbemycin $\beta_{3}$. The relative stereochemistry of $\mathbf{2}$ was assigned as that of $\mathbf{1}$. 
Two new 13-oxomilbemycins from Streptomyces avermitilis

Table 1. ${ }^{1} \mathrm{H}$ and ${ }^{13} \mathrm{C}$ NMR spectral data for $\mathbf{1}$ and 2 in $\mathrm{CDCl}_{3}$

\begin{tabular}{|c|c|c|c|c|}
\hline \multirow{2}{*}{ Position } & \multicolumn{2}{|c|}{$\delta_{\mathrm{H}}($ mult., $J$ in $\mathrm{Hz})$} & \multicolumn{2}{|c|}{$\delta_{\mathrm{C}}(\mathbf{p p m})$} \\
\hline & 1 & 2 & 1 & 2 \\
\hline 1 & & & 168.4 & 168.4 \\
\hline 2 & & & 122.8 & 122.8 \\
\hline 3 & $7.50(\mathrm{~s})$ & $7.49(\mathrm{~s})$ & 132.8 & 132.9 \\
\hline 4 & & & 123.3 & 123.2 \\
\hline 5 & & & 156.2 & 156.2 \\
\hline 6 & $6.59(\mathrm{~s})$ & $6.60(\mathrm{~s})$ & 114.4 & 114.5 \\
\hline 7 & & & 144.8 & 144.8 \\
\hline 8 & & & 137.7 & 137.7 \\
\hline 9 & $5.68(\mathrm{~d}, 10.9)$ & $5.67(\mathrm{~d}, 10.9)$ & 126.9 & 126.8 \\
\hline 10 & $6.46(\mathrm{dd}, 15.0,10.9)$ & $6.45(\mathrm{dd}, 15.0,10.9)$ & 128.9 & 129.0 \\
\hline 11 & $5.41(\mathrm{dd}, 15.0,9.5)$ & $5.41(\mathrm{dd}, 15.0,9.8)$ & 135.5 & 135.5 \\
\hline 12 & $3.93(\mathrm{~m})$ & $3.94(\mathrm{~m})$ & 46.0 & 46.0 \\
\hline 13 & & & 202.1 & 202.1 \\
\hline 14 & & & 137.7 & 137.7 \\
\hline 15 & $6.71(\mathrm{t}, 7.5)$ & $6.73(\mathrm{t}, 7.2)$ & 139.1 & 139.1 \\
\hline 16 & $\begin{array}{l}2.38(\mathrm{~m}) \\
2.64(\mathrm{~m})\end{array}$ & $\begin{array}{l}2.37(\mathrm{~m}) \\
2.65(\mathrm{~m})\end{array}$ & 33.6 & 33.6 \\
\hline 17 & $3.83(\mathrm{~m})$ & $3.84(\mathrm{~m})$ & 65.7 & 65.8 \\
\hline 18 & $\begin{array}{l}1.18(\mathrm{~m}) \\
1.96(\mathrm{~m})\end{array}$ & $\begin{array}{l}1.19(\mathrm{~m}) \\
1.95(\mathrm{~m})\end{array}$ & 35.3 & 35.5 \\
\hline 19 & $5.38(\mathrm{~m})$ & $5.38(\mathrm{~m})$ & 68.4 & 68.5 \\
\hline 20 & $\begin{array}{c}1.41(\mathrm{t}, 11.9) \\
2.03(\mathrm{~m})\end{array}$ & $\begin{array}{c}1.41(\mathrm{t}, 11.9) \\
2.04(\mathrm{~m})\end{array}$ & 40.8 & 41.0 \\
\hline 21 & & & 97.7 & 97.6 \\
\hline 22 & $\begin{array}{l}1.55(\mathrm{~m}) \\
1.70(\mathrm{~m})\end{array}$ & $\begin{array}{l}1.53(\mathrm{~m}) \\
1.69(\mathrm{~m})\end{array}$ & 35.7 & 35.6 \\
\hline 23 & $1.55(\mathrm{~m})$ & $1.53(\mathrm{~m})$ & 27.7 & 27.9 \\
\hline 24 & $1.27(\mathrm{~m})$ & $1.33(\mathrm{~m})$ & 36.5 & 34.3 \\
\hline 25 & $3.27(\mathrm{~m})$ & $3.06(\mathrm{~m})$ & 71.5 & 76.3 \\
\hline 26 & $2.25(\mathrm{~s})$ & $2.24(\mathrm{~s})$ & 15.3 & 15.3 \\
\hline 27 & $2.12(\mathrm{~d}, 0.9)$ & $2.11($ br s) & 19.3 & 19.2 \\
\hline 28 & $1.22(\mathrm{~d}, 6.7)$ & $1.22(\mathrm{~d}, 6.6)$ & 16.5 & 16.5 \\
\hline 29 & $1.81(\mathrm{br} \mathrm{s})$ & $1.80(\mathrm{br} \mathrm{s})$ & 12.2 & 12.1 \\
\hline 30 & $0.85(\mathrm{~d}, 6.5)$ & $0.84(\mathrm{~d}, 6.5)$ & 17.9 & 17.8 \\
\hline 31 & $1.14(\mathrm{~d}, 6.2)$ & $\begin{array}{l}1.33(\mathrm{~m}) \\
1.69(\mathrm{~m})\end{array}$ & 19.3 & 25.7 \\
\hline 32 & & $0.96(t, 7.3)$ & & 10.2 \\
\hline
\end{tabular}

\subsection{Nematicidal Activity}

Compounds $\mathbf{1}$ and $\mathbf{2}$ displayed moderate nematocidal activities against Bursaphelenchus xylophilus (LC50: 1, $62.24 \mu \mathrm{g} / \mathrm{mL} ; 2,127.37 \mu \mathrm{g} / \mathrm{mL}$; milbemycins A3/A4, $14.26 \mu \mathrm{g} / \mathrm{mL}$ ). 


\section{Acknowledgments}

This research was financially supported by the Key Research and Development Programs of Zhejiang Province (Grant No: 2020C02028).

\section{Supporting Information}

Supporting information accompanies this paper on http://www.acgpubs.org/journal/records-ofnatural-products

\section{ORCID}

Ji-Dong Wang: 0000-0003-4098-6209

Bing Li: 0000-0001-5465-5414

Shao-Yong Zhang: 0000-0003-3571-5797

Yi Wu: 0000-0002-2981-7589

Wen-Sheng Xiang: 0000-0002-1826-5985

Li-Qin Zhang: 0000-0002-3859-5412

Huan Qi: 0000-0003-4313-5055

\section{References}

[1] P. Przybylski (2011). Modifications and biological activity of natural and semisynthetic 16-membered macrolide antibiotics, Curr. Org. Chem. 15, 328-374.

[2] L. K. Bekele and G. G. Gebeyehu (2012). Application of different analytical techniques and microbiological assays for the analysis of macrolide antibiotics from pharmaceutical dosage forms and biological matrices, ISRN Anal. Chem. 12, 546.

[3] H. A. Kirst (1998). Recent developments with macrolide antibiotics, Exp. Opin. Ther. Patents 8, 111120.

[4] J. Huang, A. L. Chen, H. Zhang, Z. Yu, M. H. Li, N. Li, J. T. Lin, H. Bai, J. D. Wang and Y. G. Zheng (2015). Gene replacement for the generation of designed novel avermectin derivatives with enhanced acaricidal and nematicidal activities, Appl. Environ. Microbiol. 81, 5326-5334.

[5] J. Zhang, Y. J. Yan, J. An, S. X. Huang, X. J. Wang and W. S. Xiang (2015). Designed biosynthesis of 25-methyl and 25-ethyl ivermectin with enhanced insecticidal activity by domain swap of avermectin polyketide synthase, Microb. Cell. Fact. 14, 152 (12 pages).

[6] S. Srikrai and J. E. Robbers (1983). Methods for mutation and selection of the ergot fungus, Appl. Environ. Microbiol. 45, 1165-1169.

[7] V. Delić, D. A. Hopwood and E. J. Friend (1970). Mutagenesis by $N$-methyl- $N$ '-nitro- $N$ nitrosoguanidine (NTG) in Streptomyces coelicolor, Mutat. Res. 9, 167-182.

[8] B. B. Chattoo and U. Sinha (1974). Mutagenic activity of $N$-methyl- $N$ '-nitro- $N$-nitrosoguanidine (NTG) and $N$-methyl- $N$-nitrosourea (NMU) in Aspergillus nidulans, Mutat. Res. 23, 41-49.

[9] D. R. Williams, B. A. Barner, K. Nishitani and J. G. Phillips (1982). Total synthesis of milbemycin $\beta_{3}, J$. Am. Chem. Soc. 104, 4708-4710.

[10] S. R. Schow, J. D. Bloom, A. S. Thompson, K. N. Winzenberg and A. B. Smith (1986). Milbemycinavermectin studies. 5. Total synthesis of milbemycin $\beta_{3}$ and its $\mathrm{C}(12)$ epimer, J. Am. Chem. Soc. 108, 2662-2674.

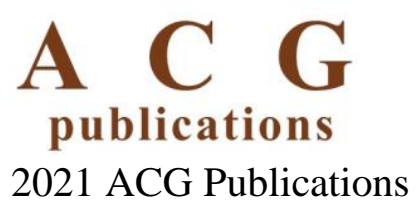

